\title{
Are European decision-makers preparing for high-end climate change?
}

\author{
Tiago Capela Lourenço ${ }^{1}$ (D) Maria João Cruz ${ }^{1} \cdot$ Adis Dzebo $^{2} \cdot$ Henrik Carlsen $^{2} \cdot$ Miriam Dunn $^{3}$. \\ Linda Juhász-Horváth ${ }^{4}$ Laszlo Pinter ${ }^{4}$
}

Received: 18 May 2017 / Accepted: 15 May 2018 / Published online: 19 June 2018

(C) The Author(s) 2018

\begin{abstract}
Despite the Paris Agreement target of holding global temperature increases 1.5 to $2{ }^{\circ} \mathrm{C}$ above pre-industrial levels, high-end climate change (HECC) scenarios going beyond $4{ }^{\circ} \mathrm{C}$ are becoming increasingly plausible. HECC may imply increasing climate variability and extremes as well as the triggering of tipping points, posing further difficulties for adaptation. This paper compares the outcomes of four concurrent European case studies (EU, Hungary, Portugal, and Scotland) that explore the individual and institutional conditions, and the information used to underpin adaptation-related decision-making in the context of HECC. The focus is on (i) whether HECC scenarios are used in current adaptation-related decision-making processes; (ii) the role of uncertainty and how climate and non-climate information is used (or not) in these processes; and (iii) the information types (including socio-economic drivers) commonly used and their limitations in relation to HECC scenarios. Decision-makers perceive HECC as having a low probability or distant occurrence and do not routinely account for HECC scenarios within existing climate actions. Decision-makers also perceive non-climate drivers as at least as important, in many cases more important, than climate change alone. Whilst more information about the implications of particular sectoral and cross-sectoral impacts is needed, climate change uncertainty is not a significant barrier to decision-making. Further understanding of individual and institutional challenges brought about by the 'squeeze' between adapting to HECC scenarios or to lower levels of temperature change (as those agreed in Paris) is essential to better contextualise the use of climate change information.
\end{abstract}

Keywords High-end climate change $\cdot$ Adaptation $\cdot$ Decision-making $\cdot$ Uncertainties $\cdot$ Paris Agreement

Electronic supplementary material The online version of this article (https://doi.org/10.1007/s10113-018-1362-2) contains supplementary material, which is available to authorized users.

Tiago Capela Lourenço tcapela@fc.ul.pt

Maria João Cruz

cruz.mjoao@gmail.com

Adis Dzebo

adis.dzebo@sei-international.org

Henrik Carlsen

henrik.carlsen@sei-international.org

Miriam Dunn

miriam.dunn@ed.ac.uk

Linda Juhász-Horváth

horvathlinda@gmail.com
Laszlo Pinter

lpinter@iisd.ca

1 Centre for Ecology, Evolution and Environmental Changes, Faculdade de Ciências, Universidade de Lisboa, 1749-016 Lisbon, Portugal

2 Stockholm Environment Institute, Stockholm, Sweden

3 Institute of Geography, School of Geosciences, University of Edinburgh, Drummond Street, Edinburgh EH8 9XP, Scotland

4 Department of Environmental Sciences and Policy, Central European University, Budapest, Hungary 


\section{Introduction}

The Paris Agreement - the outcome of the UNFCCC Conference of the Parties (COP) meeting in December 2015 - sets out a target to limit the increase in global mean temperature to well below $2{ }^{\circ} \mathrm{C}$ above pre-industrial levels along with the pursuit of efforts to limit the increase to $1.5^{\circ} \mathrm{C}$ above pre-industrial levels. Projections based on current trends point to much more substantial levels of warming, including of $4{ }^{\circ} \mathrm{C}$ or more, unless there is radical action to cut greenhouse gas emissions (Jordan et al. 2013; Gasser et al. 2015). More specifically, the latest estimates of the Intergovernmental Panel on Climate Change (IPCC) show the possibility of a $3.7-4.8^{\circ} \mathrm{C}$ increase in global temperature by the end of the twenty-first century based on current mitigation efforts, with even larger ranges $\left(2.5-7.8^{\circ} \mathrm{C}\right)$ if climate uncertainty is included (Edenhofer et al. 2014). This means that whilst the target of limiting climate change to well below $2{ }^{\circ} \mathrm{C}$ (or $1.5^{\circ} \mathrm{C}$ ) has been agreed internationally, thus recognising such level as a limit to significantly reduce risks and impacts, high-end climate change (HECC) scenarios are becoming increasingly plausible.

HECC scenarios can be described as those going beyond the $2{ }^{\circ} \mathrm{C}$ target or as representing the upper end of the range of possible futures. Such scenarios include climate and the underlying socio-economic storylines both as the drivers of emissions and as narratives capturing a range of societal challenges. These high-end trajectories will potentially lead to severe levels of climate change impacts across multiple sectors and systems, such as those described for flood risk (Alfieri et al. 2015), sea-level rise (Golledge et al. 2015), water scarcity (Schewe et al. 2014), heat stress (Sherwood and Huber 2010), among others (Field et al. 2014).

HECC scenarios were the focus of three complementary European Union (EU) projects assessing impacts and adaptation across a range of land, water, and coastal ecosystems. ${ }^{1}$ This means that whilst intergovernmental emphasis is currently on mitigation of emissions to reach the 1.5 to $2{ }^{\circ} \mathrm{C}$ climate target, the EU recognises - via its funded projects - that good risk management involves preparing for higher levels of adaptation than we hope are necessary.

Partial results of this research were previously published in Dunn et al. (2017), focusing on how land resource managers in Scotland are preparing to deal with HECC scenarios. The present paper expands and complements that previous analysis with work from three additional case studies (EU, Hungary, and Portugal) and draws conclusions for a wider set of sectors, scales, and decisionmaking processes

In addition, the Paris Agreement targets are factored in, revealing some of the challenges facing adaptation-related decision-making, now 'conflicted' between these targets and the

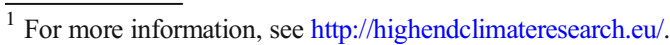

prospects of HECC. How adaptation to the $1.5{ }^{\circ} \mathrm{C}$ limit (vs. HECC) will occur in practice depends on individual and collective decision-making, and so, understanding the conditions influencing decision-makers is a step towards producing information that supports their capacity to adapt.

\section{Background}

Different pathways of socio-economic development can lead to societies that vary widely in drivers of emissions and land use as well as in their capacities to mitigate emissions or undertake adaptation measures (O'Neill et al. 2014). Adaptation to climate change is made up of actions spanning various actors across society, including individuals, groups, and governments (Adger et al. 2005; Adger et al. 2007), and more recently also across borders (Dzebo and Stripple 2015). Adaptation can include building adaptive capacity - that is, increasing the ability of societies and/or individuals to adapt to changes - and/or implementing adaptation decisionswhich requires using those capacities and transforming them into action (Adger et al. 2005; Tompkins et al. 2010). Adaptation can be seen as a continuous stream of activities (including research), actions, and attitudes that inform decisions about all aspects of life (Tompkins et al. 2010).

Such adaptations can include both public and private sector changes. Individual and organisational actions are usually constrained by institutional processes such as regulations, laws, property rights, and social norms (Adger et al. 2005; Adger et al. 2007), as these shape and influence the range of choices available to society (Jones et al. 2014). Demography, cultural and economic aspects, available technologies, and capital as well as social conventions, psychology, language, and ethics are among the many factors known to influence or constrain adaptation, in particular by shaping different views about its goals and objectives (Adger et al. 2005; Adger et al. 2009; Jones et al. 2014). When complex environments interact with conflicting values, the resulting challenges can be described as 'wicked' problems, harbouring diffuse boundaries, different framing by different groups and individuals, unclear solutions, and large and 'deep' scientific uncertainties that are not easy to quantify (Jones et al. 2014). This has been the case of adaptation-related decision-making, leading formal assessments to move from a technocratic and expert-led exercise towards a more participatory process of decision support (Jones et al. 2014), also referred to as transdisciplinarity (Pohl and Hadorn 2008; Kirchhoff et al. 2013).

Emerging risks from the potential impacts of climate change arise not only from how the future is described, but also from the uncertainty, actual or perceived, surrounding that description (Eiser et al. 2012; Willows and Connell 2003). Evidence gathered through decision sciences demonstrates that 'good' scientific and technical information alone may be insufficient to assure 'better' decisions (Pidgeon and 
Fischhoff 2011; Kirchhoff et al. 2013). Eiser et al. (2012) argue that risk-related decision-making under uncertainty is no longer adequately described by traditional 'rational choice' models and that attention needs to be paid to the way personal interpretations of risk are shaped by beliefs, values, and societal dynamics. McNie (2007) highlights that concentrated efforts in increasing the supply of scientific information may well not be producing the sorts of information decisionmakers see as relevant and useful. Pidgeon and Fischhoff (2011) argue that in order to realise the potential of climaterelated research, decision-makers need to understand the risks and uncertainties that are relevant for the decision they face. However, promoting that understanding may well not be a sufficient condition for effective adaptation (and mitigation) responses to the risks posed by climate change, since large political and physiological barriers will also need to be tackled.

Climate change creates an additional layer of uncertainty for decision-makers, who already face multiple short-term and strategic economic, social, and political (i.e., non-climate) challenges, leading to double exposure (O'Brien and Leichenko 2000). Despite improvements in the climate change science-policy interface (Rayner and Jordan 2010), most decision-makers do not routinely consider future scenarios when making decisions, nor do they find it easy to make use of available knowledge on climate change and impacts (Dessai et al. 2005; Hulme and Dessai 2008; Porter et al. 2012). A common problem is the mismatch between the scale of what is known about the world and the scale at which decisions are made and action taken (Kates et al. 2001). Multiple conceptualisations around the barriers, limits, and enablers to adaptation action have been put forward in the literature for different scales and sectors (Lorenzoni et al. 2007; Eisenack et al. 2014; Jones et al. 2014). Such concepts have also been challenged on various grounds, especially when extrapolated across societies and contexts (Adger et al. 2009; Biesbroek et al. 2015).

The management of uncertainties and the related approaches that support climate decision-making are often framed as either a 'predict-then-act' or an 'assess-risk-of-policy' framework (Lempert et al. 2004; Jones et al. 2014). The literature referring to such approaches is extensive and often produces nuanced terms for both. Therefore, the former paradigm is also known as 'top-down, 'model-first', 'impactsfirst', science-first', or 'standard' approach, whilst the latter is also called 'bottom-up', 'context-first', 'decision-scaling', 'vulnerability, 'tipping point', 'critical threshold', or 'policyfirst' approach (Jones et al. 2014). Other definitions for these two opposing, but often complementary approaches include the terms 'predictive top-down' or 'optimization' versus 'resilience bottom-up' or 'decision-first' (Dessai and van der Sluijs 2007; Capela Lourenço et al. 2014). For simplification sake, we refer to these two approaches (which in practice reflect different schools of thought) as climate-centred (first case) or decision-centred decision-making (second case).

These approaches are important in recognising how uncertainties are managed and how they are used in adaptationrelated decision-making support, including the heuristics (Preston et al. 2013), methods, and tools applied and the engagement level of decision-makers (Willows and Connell 2003; Swart et al. 2014). Climate-centred frameworks assume that adaptation-related decisions are most importantly influenced by climate projections and do not recognise that climate is only one factor, among many others, affecting those decisions. In contrast, decision-centred adaptation puts climate into perspective within the decision-making context and considers all of the contributing factors, as for example, economic priorities, environmental issues, political and social factors, demographics, and regulation (Dunn et al. 2017). These approaches seem to play a role in affecting the way decisionmakers choose to adapt, for example, when considering incremental versus transformative changes (Dunn et al. 2017).

From a natural science perspective, HECC may imply increasing climate variability and extremes (Lavell et al. 2012) as well as the possibility of triggering tipping points (Lenton et al. 2008), posing further difficulties for assessments, and increasing uncertainty about future impacts. From a societal point of view, HECC can generate difficulties in processing and using information about highly extreme and uncertain futures, hindering the capacity to respond, as there are potential psychological, social, and institutional barriers to adapting to a world much warmer than today (Stafford Smith et al. 2011). HECC may push ecosystems and societies beyond their limits of adaptation (Dow et al. 2013; Klein and Juhola 2014), thus resulting in loss and damage (James et al. 2014) and raising additional problems for decision-making.

The theoretical foundations discussed above were used to address some key research questions: Are HECC scenarios currently used in the adaptation decision-making processes of sectors that will need to deal with the potential impacts of climate change? If so, are they acting to adapt in line with the high-end impacts, or conversely, are they considering adaptation actions in line with more moderate levels of future climate change such as the ones agreed in Paris? What sorts of information are being used for adaptation-related decision-making (including non-climate drivers)? What are the barriers regarding the use of that information? And finally, what is the role of uncertainty in the adaptation-related decision-making processes?

\section{Methods}

A set of semi-structured interviews were conducted with decision-makers across the four case studies to collect empirical data about their adaptation-related decision-making 
processes and respective information and support needs. The interviews focused on current decision-making processes and how these may need to change in relation to high-end scenarios, so as to investigate the question of what is different about decision-making that considers high-end futures. Personal perspectives obtained through the interviews were recorded and transcribed, and the content was analysed inductively.

In line with Dunn et al. (2017), four key themes were explored in the interviews: (1) the use of climate change information in adaptation-related decision-making processes; (2) the limitations and challenges of using climate change and HECC information; (3) the implications of uncertainty for adaptation; and (4) the use of non-climate information and its influence in adaptation-related decision-making processes. Additionally, the number and diversity of interviewees allowed exploring the implications of the $1.5^{\circ} \mathrm{C}$ Paris target vis-à-vis HECC scenarios, for adaptation-related decisionmaking. These emergent themes are explored in the following sections and discussed against the theoretical underpinnings presented in 'Introduction'.

The analysis methods are presented below: firstly, a brief overview of the objectives in each of the case studies used in this work, followed by an introduction to the HECC scenarios considered, and finally a description of the overall data collection and of the analytical process applied, including the limitations of how the data and results should be used.

\section{Research area-case studies}

The research presented here covers four case studies, one European and three regional/local cases: Hungary, Portugal, and Scotland. These case studies were selected to provide comparable empirical data and address the research objectives described above.

\section{European case}

The European case study was used to quantify cross-sectoral HECC impacts and vulnerabilities with the aim of developing adaptation and mitigation pathways that address them within the EU27. The sectors under analysis included agriculture, forestry, water, urban development, human health, coastal areas, and biodiversity.

\section{Hungarian case}

The case study for Hungary aimed at exploring multi-sectoral interactions and responses to HECC in two medium-size towns, Veszprém and Szekszárd, located in Western Hungary. The sectors studied include water, agriculture, and human health (focusing on heat stress) with multi-scale issues like water management, local/regional food supply, and related land use issues also being considered.

\section{Portuguese case}

The goal of the Portuguese case study was to explore multisectoral and transboundary interfaces in a southern European environment, including water resource management, agriculture, forestry, and biodiversity. The Portuguese case study was part of a larger Iberian case that looked at transboundary water and land resource management and that specifically focussed on the transboundary basin of the Tagus River, one of the five international river basins shared between Portugal and Spain.

\section{Scottish case}

The case study in Scotland aimed at analysing multi-sectoral interactions in a north-western European environment. With a focus on land resource management, this case study assessed the agriculture, forestry, water, and tourism sectors, along with the multi-scale issue of supply chains for food and beverages (Dunn et al. 2017).

\section{High-end climate change scenarios in Europe}

The HECC scenarios referred to in this work were sourced from spatial (mapped) model output of projected temperature and precipitation changes for the early, middle, and late twentyfirst century. This model output was sourced directly from project partners (Madsen et al. 2016) at the Danish Meteorological Institute who produce output from the HadGEM Earth System Model, downscaled to a spatial resolution of $50 \mathrm{~km}$. The 'high end' of emissions refers to representative concentration pathway 8.5 , the highest of the IPCC's current emission pathways (Moss et al. 2010; van Vuuren et al. 2011).

\section{Data collection and analysis}

In total, 53 in-depth face-to-face interviews were conducted with 61 decision-makers at various locations across all four case studies between February and October 2015 (see Table 1 for details). Despite being carried out by different interviewers, all interviews derived from the same original common questionnaire. Interviews ranged in duration between half an hour and $2 \mathrm{~h}$, depending on the responses given by the interviewees. For logistical convenience, some of the interviews were conducted in small groups, but all responses were recorded for each individual decision-maker.

For each case study, decision-makers were identified and selected from a wider stakeholder list, (Table 1). They were contacted directly by the interviewers or via local contacts. Only stakeholders involved either in direct adaptation decision-making processes or adaptationrelated processes through their own sectoral work were selected to be interviewed. 
Table 1 Details of the interviews with decision-makers in the four case studies, including total number of stakeholders involved in the case study, time interval of interviews, total number of interviews carried out and total number of decision-makers interviewed

\begin{tabular}{|c|c|c|c|c|}
\hline & \multicolumn{4}{|l|}{ Case study } \\
\hline & European & Hungary & Portugal & Scotland \\
\hline $\begin{array}{l}\text { Total no. stakeholders } \\
\text { involved in case-study }\end{array}$ & 77 & 74 & 67 & 39 \\
\hline Time interval of interviews & $\begin{array}{c}\text { September-October } \\
2015\end{array}$ & $\begin{array}{l}\text { April-October } \\
2015\end{array}$ & $\begin{array}{l}\text { February-October } \\
2015\end{array}$ & $\begin{array}{l}\text { March-June } \\
2015\end{array}$ \\
\hline Total no. of interviews & 12 & 12 & 9 & 20 \\
\hline $\begin{array}{l}\text { Total no. of decision-makers } \\
\text { interviewed }\end{array}$ & 17 & 12 & 12 & 20 \\
\hline
\end{tabular}

The wider case study stakeholder lists were sourced against numerous criteria, based on a matrix developed and tested in similar stakeholder research by Gramberger et al. (2015) to achieve representativeness across categories. These criteria included demographics, sector, level of operation of the organisation, function of the stakeholder, level of operation of the stakeholder, and organisational affiliation. The final selection of stakeholders consisted of representatives from different sectors, with different affiliations (e.g., government, economy, enterprises, civil society, and research) and different functions within organisations operating at different scales (e.g., local to European), across a wide range of demographics.

Because of the differences between case studies, the list of sectors covered was substantial and included among others: water, infrastructure, energy, finance/insurance, agriculture, food/nutrition, whisky production, forestry, biodiversity conservation, tourism, health, land use/land use management, and security.

The interviews were framed by a decision-centred approach focusing on adaptation-related decision-making processes. The empirical data collection was guided by the research questions stated in 'Introduction'. The interviews focused on individual, collective, and institutional conditions that underpin decision-making processes. A common frame of reference for climate adaptation-related decision-making analysis (first presented by Capela Lourenço et al. (2014)) was applied to the development of the common interview template. This frame of reference allowed the structuring of the interviews around three main dimensions of the assessment: decision-making objectives, decision support, and decision-making outcomes.

The original interview template guide consisted of 15 questions, with multiple sub-questions under each dimension that focused on the context and support for adaptationrelated decision-making. Although the overall structure and key dimensions under assessment were maintained, the final interview templates varied between case studies, due to their interviewee contexts. Because of the pan-European nature of the case study, the interviewees in the European case were interviewed in direct respect to the policy areas they worked on (i.e., Common Agricultural Policy, Flood Directive, Forest Strategy, Habitats Directive, and Water Framework Directive). The European interview template reflected these policy areas and titles but all questions were the same across templates. All the interviews were recorded and transcribed, then analysed and reported back to the interviewees. The four interview template guides used in this work are available in Electronic Supplementary Material I.

There were limitations in how the data could be analysed and therefore how the results should be used. These limitations draw not only from the wide range of sectors and policy areas included in the process, but also from the fact that the case studies compare experiences across three different countries as well as across the policy settings of the European Union. Although each of these countries operates under the common framework of policy-making decided by the EU, they also have specific local context and issues. Some of these issues are common across case studies, but others are unique to the case study due to its particular social, political, and environmental context. The following results should be interpreted with the above limitations in mind.

\section{Results}

The following sections answer the research questions described above. The cross-case study assessment framework provided coverage of a wide spectrum of adaptationrelated sectors and decision-making processes. In turn, this provided coverage of a wide diversity of social and institutional settings. To highlight these multiple contexts, the following section briefly characterises the adaptationrelated decision-making processes the interviewees were involved in. The subsequent sections present results on the following: the use of climate change and HECC information; the limitations and challenges of using that information; the implications of uncertainty; and the use of nonclimate information and its influence in adaptation-related decision-making processes. 


\section{Decision-making contexts and objectives}

The type of organisations and the level of individual involvement in institutional decision-making processes of the 61 interviewees were quite variable. A large proportion of respondents were working for governmental agencies, but this type was skewed by the EU case study where all 17 respondents considered themselves as working for a (supra) governmental agency. In the three regional/local cases, government affiliation was also the most common, but was closely followed by companies/enterprises, inter-institutional networks, and practitioners/planners.

The respondents covered a wide range of sectors (see Fig. 1) with biodiversity conservation, water, and land use/ land management being the most represented. These were followed by agriculture, forestry, infrastructure, energy, and health. A significant number of decision-makers characterised their roles as working across sectors (except in the EU case) or in the climate 'sector' (except in the Scottish case).

Respondents were mainly involved at the national or municipal/local scale, followed by European and regional. Because of the different contexts across case studies, significant differences in scale were expected. For example, all European case study respondents see themselves working at the EU-level, whilst in the Hungarian case study, due to the focus on two municipalities, the interviewed decision-makers saw themselves as predominantly local. In the Portuguese and Scottish cases, the spread is wider with all scales represented.

By design, all respondents were expected to be involved in adaptation-related (or climate-) decision-making processes, a situation that was confirmed during the interviews. However, because of the mixture of types of organisations and operational levels involved, the meaning of adaptation action varies significantly across case studies not revealing a clear pattern. About half of the respondents (51\%) stated that their adaptation-related decisions (where they were being made) were strategic in nature and significantly conditioned by the institutional settings where they operate in. These were followed by operational (30\%) and regulatory (19\%) types of decisions. With the exception of the European case study where all respondents stated they were only dealing with strategic decisions, a large number (86\%) of respondents in the national/local cases indicated that they were simultaneously involved in multiple types of decision-making processes (e.g., strategic and operational).

Regarding the lifetime of the decision-making processes, respondents noted they are typically involved in making adaptation-related decisions that have short $(36 \%)$ to medium (45\%) lead times and medium (36\%) to long (44\%) consequence times, equating to long decision lifetimes.

\section{Use of climate change information in adaptation-related decision-making}

Interview results indicate no particular constraints in the access to climate change information (high-end or not) and point that its use in the decision-making processes is rather common (Fig. 2, left). However, it also shows that limitations in the use of this sort of information are also commonly reported by decision-makers (Fig. 2, right). As to the usefulness of this information in helping making decisions (adaptation-related or not), a different case emerges. In two of the cases where more detailed information is available, Scotland and Portugal, between one third and half of the respondents agree that climate change information has proven useful and helped making adaptation-related decisions. Interestingly, rather than replying negatively to the question about how helpful was the climate change information to the decision-making
Fig. 1 Distribution of participant's responses about the main sector of work they operate in. Note that the number of responses $(n=121)$ is greater than the number of participants $(n=61)$ because each participant could report multiple sectors

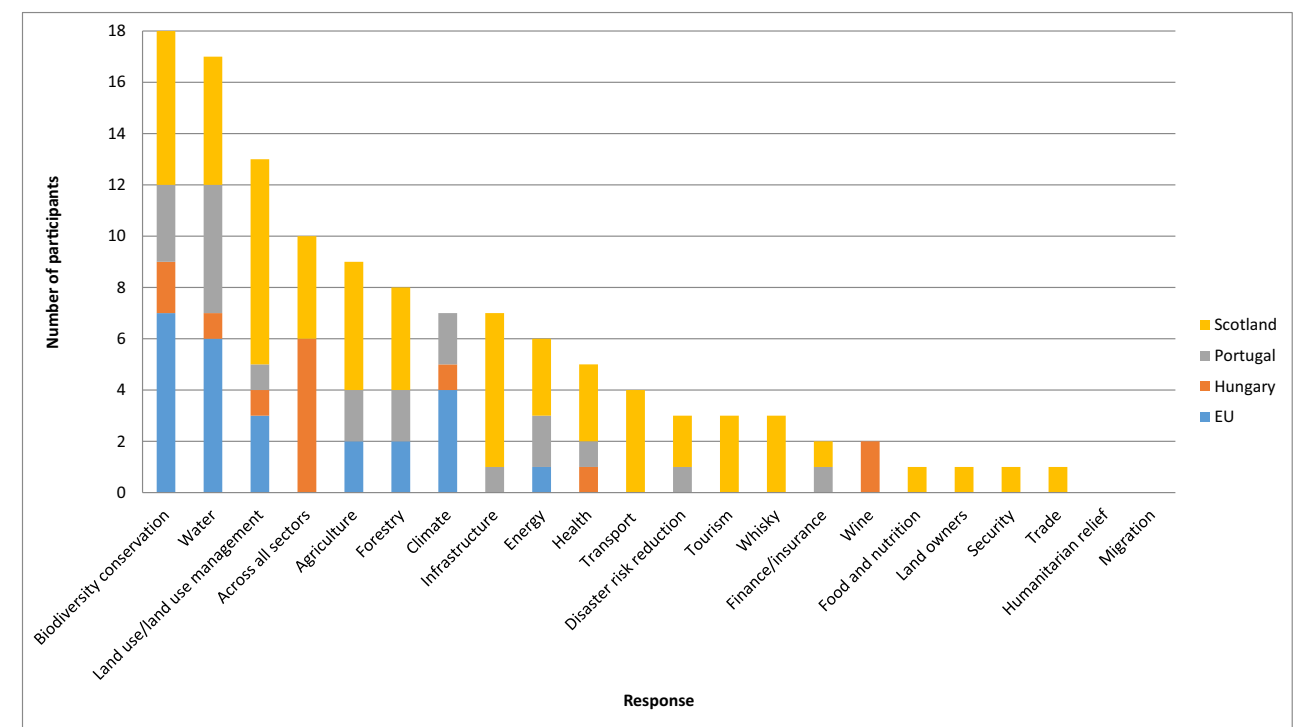



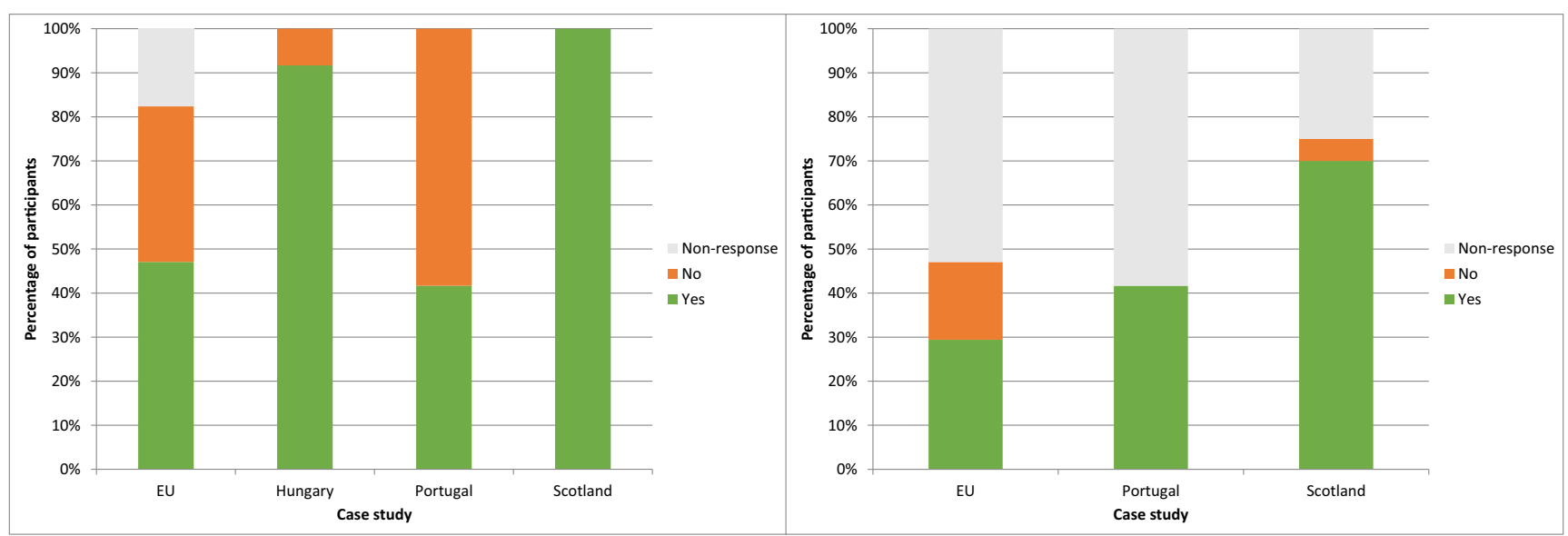

Fig. 2 Percentage of responses per case study, to the question whether climate change information is used by participants in their decision-making processes (left; $n=61)$ and if they find any limitations in the use of this sort of information ( $r i g h t ; n=49 ;$ no data available for Hungary)

processes, the remaining participants preferred not to answer or state they were unsure.

Regarding the more specific matter of access and use of HECC information and its influence in adaptation-related decision-making processes, results show that HECC projections seem to be available and used (Fig. 3, left), but that they only go as far as to influence decision-making (Fig. 3, right). This influence is very variable and seems to be case study contingent, with Portuguese respondents stating no influence whatsoever whilst over $60 \%$ of Scottish participants mentioning that HECC information did play a role in their adaptation-related decisions. EU participants tend towards smaller levels of influence (around 25\%), whilst no data was available for Hungary.

HECC information is reported as being partially used as background knowledge when decisions are made or as influencing the types of information decision-makers provide to other decision-makers (for example higher levels) when advising them on decisions (Scottish case). Nevertheless, with the exception of Hungary, HECC is consistently considered as one of several options regarding future levels of climate change, not the only nor the most probable one.

Additionally, results from the EU and Scottish case studies point towards a discrepancy related to the mismatch between statements that HECC has influenced decision-making but that the organisation is not specifically considering changes above the $1.5-2{ }^{\circ} \mathrm{C}$ Paris thresholds. Several reasons were put forward to explain this difference including the respondent's acknowledgement that current adaptation decision-making processes do not consider specific temperature changes as particularly relevant since they are generally focusing on robust actions. Additionally, another reason noted was that, for the most part, respondents were more concerned with impacts and consequences of change that can be discussed using qualitative levels of change, rather than specific global temperature thresholds (e.g., 2 vs. $2.5^{\circ} \mathrm{C}$ and so forth). These explanations are also consistent in the Portuguese case where, although respondents did not recognised any influence of HECC

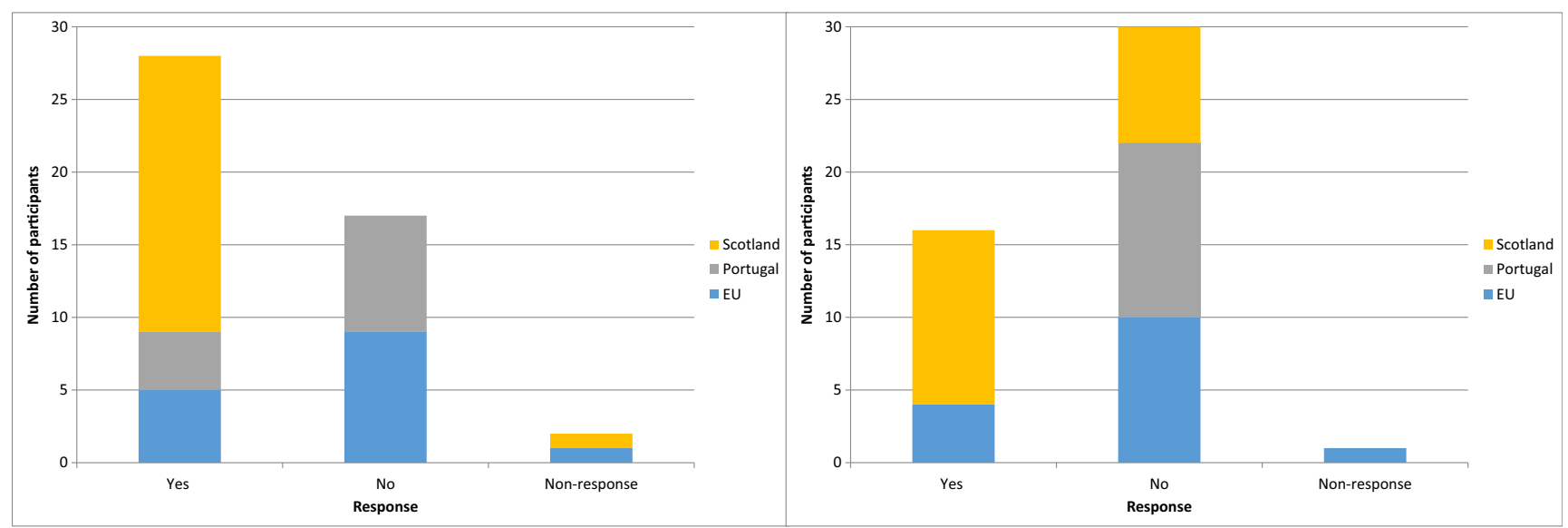

Fig. 3 Number of responses to the question if participants have previously received information about high-end climate change (HECC) (left) and if this information had influenced their adaptation-related decision-making processes (right) ( $n=49$; no data available for Hungary) 
scenarios in their current decision-making, they acknowledge that this may change in the near future.

When asked about the implications of change above the $1.5-2{ }^{\circ} \mathrm{C}$ global thresholds, answers pointed towards the need to incorporate such 'new' knowledge in decision-making processes and models, as well as the need to anticipate already identified actions and their timings, and being more 'effective' in their implementation. Such perspectives seem consistent across cases, sectors, and scales, with more than $60 \%$ of respondents acknowledging that whilst HECC will most likely have implications for their current policies goals and decisionmaking processes, preparing for HECC scenarios is still not a priority.

\section{Challenges and barriers to the use of climate change information}

When questioned on existing limitations to the use of climate change (HECC or otherwise) information for decision-making, the views expressed by the participants point towards issues of usability and availability of specific types of climate information rather than about uncertainty in the information (Fig. 4).

Participants' responses indicated that information is not usable because of the following: (i) it is not adequately tailored to the decision-making circumstances (e.g., variables, spatial, and timescales), (ii) there is a lack of cross-sectoral information and it is often not presented in a format that is usable (or translated out of 'researcher language'), and (iii) some barriers on the usage of data formats still remain.

For example, on a related question about the use of models in support of decision-making (not shown here), over $90 \%$ of the interviewees in the Hungarian case study reported no access to nor use of model-related outputs in support of their organisation's decision-making. The main reasons given were lack of funding to develop and run models customised to the local context alongside the lack of expertise.

More specific gaps on the necessary information for adaptation-related decisions were case study or individual driven, with no clear pattern emerging across cases or types of organisations. These included lack of HECC projections of fire risks, future storms and flood events, habitat suitability, water availably and quality, food production, land use, and economic implications.

\section{Implications of uncertainty for adaptation}

Results show that climate change uncertainty, referring to the uncertainty of projected climatic changes, is a familiar term to participants and is usually discussed and understood by them primarily in qualitative, descriptive terms or not communicated at all (Fig. 5).

When asked about how uncertainty regarding future climate change and socio-economic factors is taken into account and communicated within their organisations, most respondents in the EU case (64\%) did not provide an answer or stated they are not aware of a formal way of communicating uncertainty. In the Portuguese case, about one third replied they did not have an answer whilst another third stated that uncertainty is not communicated. Finally, in the Scottish case, $92 \%$ of the responses point towards some way of communicating uncertainties with a large number of those responses (42\%) mentioning that it is done mostly through qualitative descriptions.
Fig. 4 Categorisation of participants perceived limitations in the use of climate change information for decision-making. Please note that due to differences in interviews across cases, results were drawn from different questions and the total number of participants is lower since some participants opted to not reply ( $n=35$; no data available for Hungary)

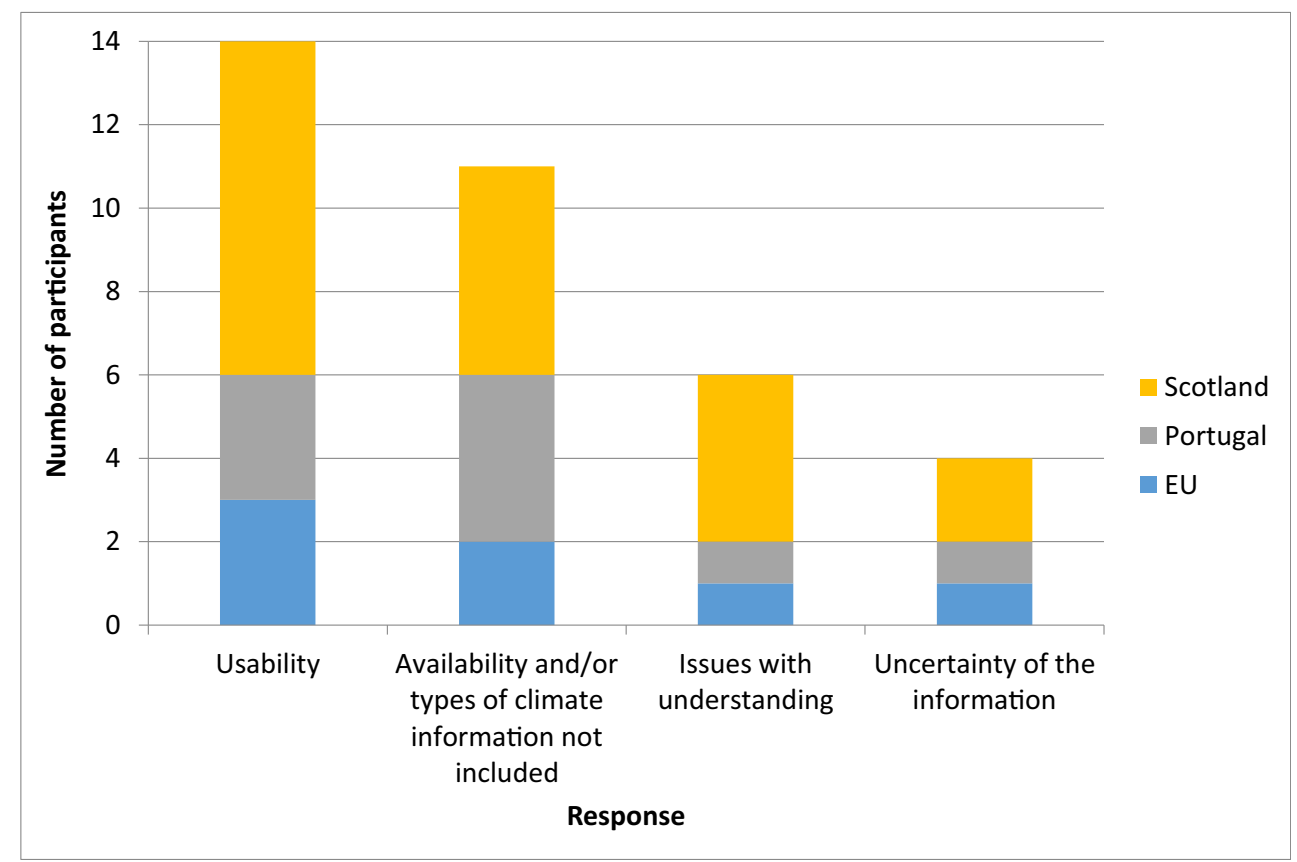


Fig. 5 Distribution of responses about how climate change uncertainty is communicated and accounted for within the adaptation-related decisionmaking processes of the participant organisations. Note that the total number of responses $(n=52)$ is greater than the number of participants $(n=49$; no data available for Hungary) because each participant could give multiple answers

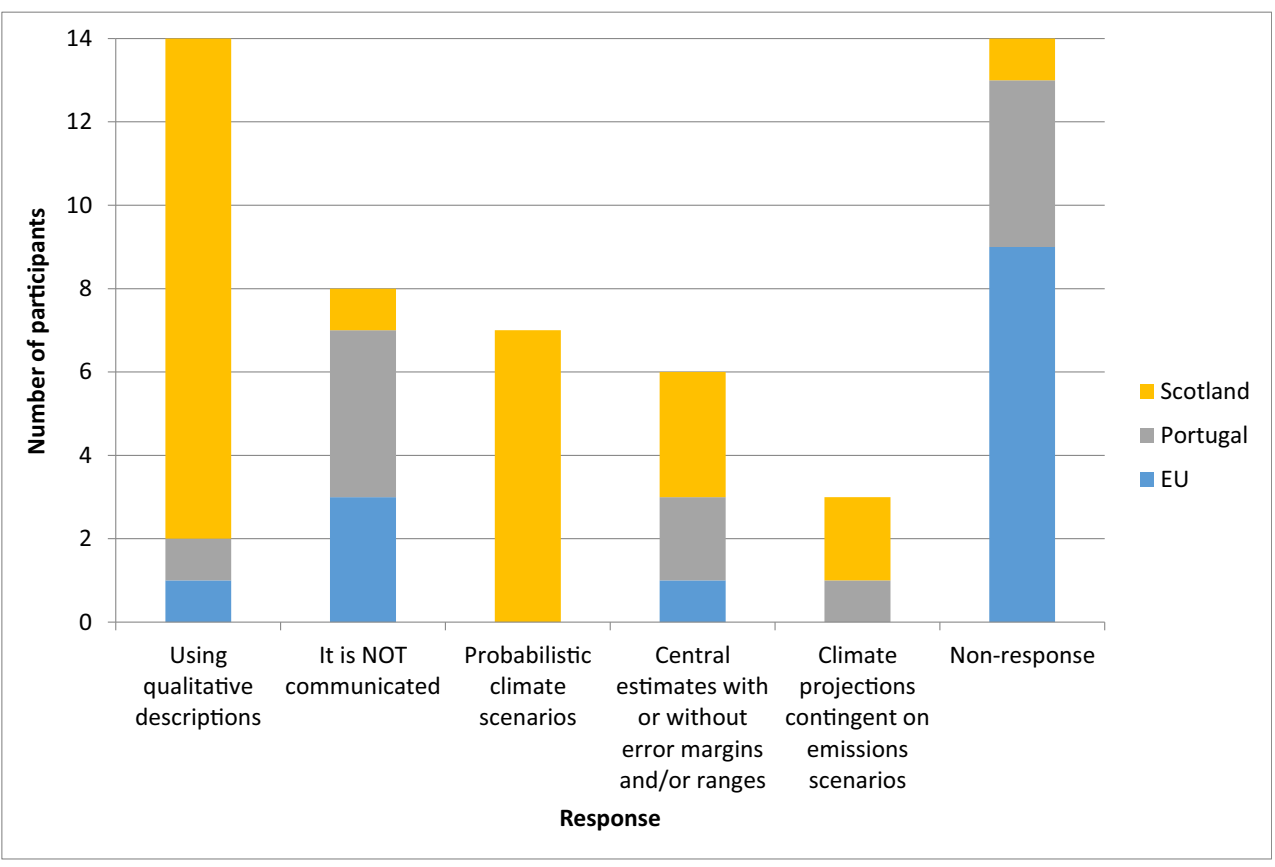

These differences across case studies often relate to the institutional settings and previous experience within EU research projects (e.g., Scottish decision-makers). The connections between familiarity with climate data uncertainty and research projects (national or international) were referred to by many participants across all the three cases, pointing to the influence of those projects in their knowledge about what uncertainty 'means' and its role in decision-making.

Nevertheless, in a broad sense, uncertainty was not perceived as a major obstacle to adaptation-related decision-making processes nor to the consideration of HECC scenarios in those same processes.

Some of the reasons pointed out include the notion that uncertainty is still very much discussed at a technical level not reaching the same degree of importance when it comes to making the decisions per se and that most of the current adaptation-related decisions are made with robustness in mind. Additionally, in the EU case study, it was noted that the perception of uncertainty is often different between the European Commission and the Member States, which leads to opposite notions of how such uncertainties should (or not) be included in the decision-making (and reporting) processes.

Results from these cases do not show a clear pattern in terms of what the uncertainties associated with HECC scenarios as well as the Paris agreement targets mean for adaptation. As mentioned above, current decision-making processes appear as 'insensitive' to specific levels of global temperature change and tend to focus more on the impacts and consequences at their respective scales or institutional interests. Responses highlight a greater focus on the perceived uncertainty around climate impacts at individual case scale, rather than global targets or pathways.

\section{Socio-economic factors influencing adaptation-related decision-making}

Participants pointed out that climate is only one aspect of adaptation-related decision-making, and it is often not the most important aspect, with several key non-climate factors being, in many cases, at least as important.

Overall, the most mentioned key non-climate socio-economic factors of influence (Fig. 6) were as follows: environmental degradation, water resources, land-use change, agricultural productivity, and infrastructure. The overall results were slightly skewed by the EU case study participants that provided a significant contribution (more than half of the responses) to the more generic factor of environmental degradation. In the EU case, this factor was followed, but with significantly less mentions, by energy, agricultural productivity, and food security.

In the Hungarian case study, the most mentioned factors were infrastructure and governance regimes, followed closely by environmental degradation, land-use change, agricultural productivity, transport and mobility, GDP growth, and business and finance. Respondents in the Portuguese case mainly highlighted environmental degradation, followed by water resources and population growth. Finally, in the Scottish case, the most mentioned key factor was tourism, closely followed by water resources, land-use change, and health.

Interview results point towards a generalised perception that adaptation-related decision-making processes will be at least as affected by (non-climatic) socio-economic factors as they will be by climate change, if not more.

Additionally, respondents across all case studies acknowledge that other cross-cutting factors deserve further 


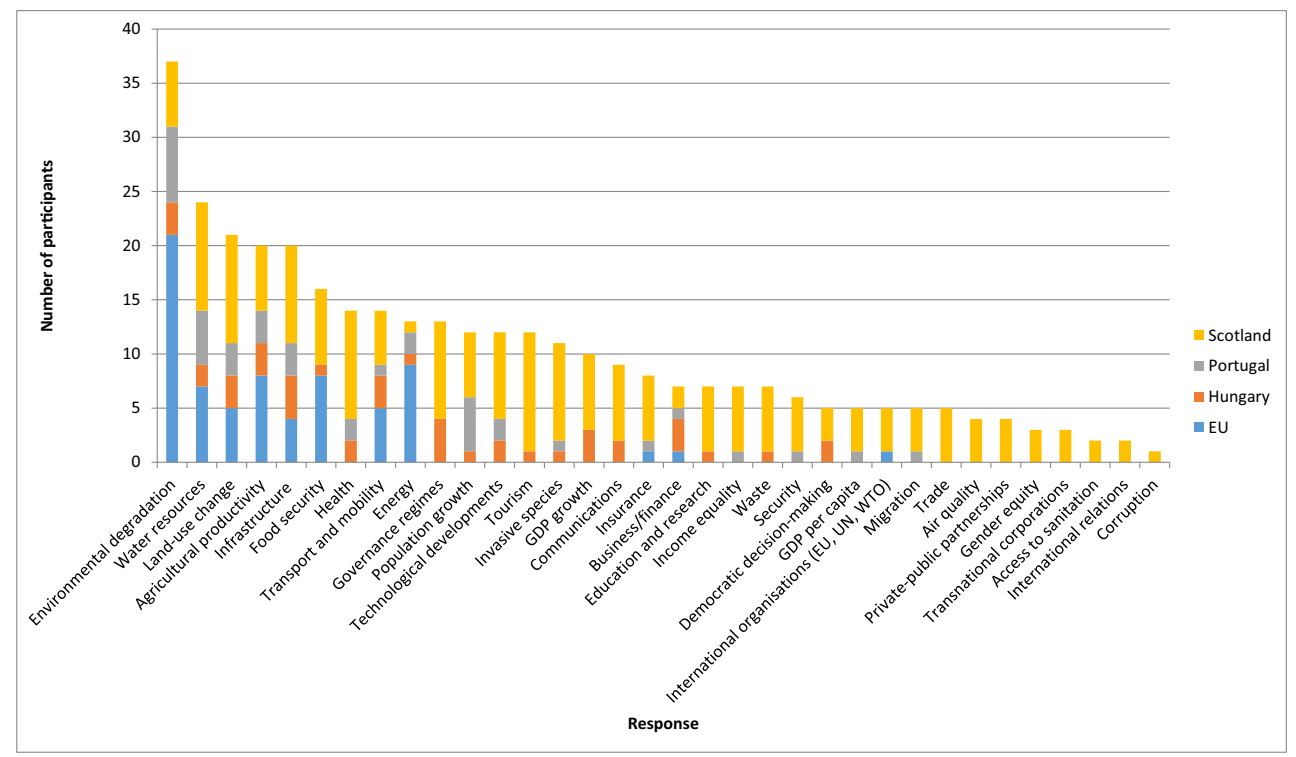

Fig. 6 Distribution of participant's responses about the key (non-climate) socio-economic factors considered the most important ones for their adaptation-related decision-making processes. Note that the number of responses $(n=344)$ is greater than the number of participants $(n=61)$ because each participant could report multiple factors attention since they may eventually emerge as some of the key inhibitors of adaptation to HECC scenarios, namely, policy and planning cycles, mismatch of actions across scales, and the need to act on existing risks versus longterm scenarios.

\section{Discussion}

Results presented here support the notion that HECC scenarios, per se, are neither seen as more likely or urgent by decision-makers involved in the four case studies (EU, Hungary, Portugal, Scotland), nor are they generally perceived as more useful for current adaptation-related decision-making processes. Multiple explanations for this situation can be advanced, including as follows: the presence of cognitive biases and judgement heuristics, the influence of institutional contexts and timings, the presence/absence of enabling conditions for the uptake of climate change information, the presence/absence of barriers to the practical application of that information, and the lack of a broader contextualisation of adaptation decisions within the larger set of decision-making processes faced by institutions and individuals.

However, HECC scenarios are acknowledged as a potential springboard for anticipating the implementation of adaptation actions. The lifetime of the adaptation decision is known to be a key factor determining whether planning needs to address a relatively certain set of changes or allow for diverging and different climate futures
(Stafford Smith et al. 2011). This means that actions to address HECC scenarios are required to be taken swiftly if such scenarios are anticipated to occur sooner than previously thought. These lend additional constrains for decision-makers facing the prospects of HECC scenarios on one hand and institutional settings that are targeting the $1.5{ }^{\circ} \mathrm{C}$ Paris goal on the other.

Some decision-makers' perception of HECC scenarios as being "too far-fetched" "r the mention that 'discussions around HECC are more focused on the terms of not getting there, 3 may explain the lack of urgency placed on adapting to these scenarios despite evidence that global emissions are still trailing above Paris targets. Results suggest that available scientific evidence around HECC is not being properly relayed in ways that are meaningful for current decision-making processes. Additionally, evidence about HECC developed in the context of global exercises may not be finding its way into heuristics and decision support instruments at lower scales, particularly at the regional or local level, including the needed customisation of cross-sectoral adaptation decision support tools.

The findings in this paper point towards a contradiction in statements that simultaneously refer to an influence of HECC scenarios in adaptation-related decision-

\footnotetext{
${ }^{2}$ As mentioned by interviewees in the EU (Common Agricultural Policy; Floods Directive), Scottish (Agriculture; cross-sectors), and Portuguese (Biodiversity; cross-sectors) case studies.

${ }^{3}$ As mentioned by interviewees in the EU (Floods Directive; Forest Strategy), Scottish (cross-sectors; Water), and Portuguese (Agriculture; Infrastructure; Water) case studies.
} 
making whilst recognising that organisations are not specifically considering changes above the $1.5-2{ }^{\circ} \mathrm{C}$ thresholds. This is consistent with previous studies on the barriers, limits, and enablers of adaptation (Adger et al. 2009; Biesbroek et al. 2015), but raises important new questions about the still incipient usability of HECC information vis-á-vis information on more moderate levels of temperature increase, for most adaptationrelated decision-making processes.

Additionally, the results of this work reinforce the perspective that climate change uncertainty is not currently perceived as a critical barrier to the prospective implementation of adaptation decisions (as put forward by, e.g., Dessai et al. 2009 and Capela Lourenço et al. 2014). However, they also raise the potential emergence of a conflicted decision-making policy and practice arena, now pressed to adapt in line with the more moderate levels of future climate change agreed in Paris, whilst facing the non-negligible prospects of HECC scenarios. A particularly interesting area for future debate is the presence or absence of enablers to the uptake of HECC information and its influence on climate services and other support mechanisms to practical climate action (Burch 2010; Lemos et al. 2012; Capela Lourenço et al. 2016; Jones et al. 2016).

These results support the notion that to achieve proper contextualisation of adaptation decisions within the larger set of decision-making processes faced by institutions and individuals, greater efforts need to be placed in providing information that supports and targets decision-centred approaches to climate and HECC scenarios. Although decision-centred approaches are increasingly acknowledged, climate adaptation-related policy and practice seem to continue to be dominated by climate-centred approaches. Nonetheless, the multitude of non-climate factors influencing decision-making processes, along with institutional conditions such as short policy cycles versus long-term thinking, hinders the necessary focus on HECC and eventually makes targeted adaptation action less probable.

Results presented here are in line with previous analysis for the Scottish case (Dunn et al. 2017) and reinforce the notion that tailored, cross-sectoral approaches are still not the norm, although perceived as necessary to support adaptation. For example, guidance on the impacts of nonclimate factors, showing sector-specific implications (Bizikova et al. 2009), is needed. Our results demonstrate that it is not more precise temperature projections that adaptation-related decision-making processes require at this stage, but rather better contextualised impacts, adaptation, and integrated vulnerability information and assessments.

Because of differences at regional and local levels, these results should be interpreted and used with the limitations of their applicability in mind. ${ }^{4}$ Namely, whilst they suggest overarching issues within some institutional arrangements at the European level, which are likely to have impact in EU Member States, they are only directly applicable if the different institutional contexts of the particular countries and sectors described are taken into account, as well as their pre-existing levels of experience in dealing with climate-related decision-making.

For political reasons, climate change decision-making is increasingly steered towards a decision space that needs to be in line with the more moderate levels of future climate change as agreed in Paris $\left(1.5-2{ }^{\circ} \mathrm{C}\right.$ targets). At the same time, current development pathways force decision-makers to face the non-negligible prospects of HECC scenarios (> $2{ }^{\circ} \mathrm{C}$ ). The decision-making landscape has thus been transformed into something with two extreme outcomes and 'nothing in between', bringing about new implications and challenges for adaptation at all scales and across sectors, and that should be the subject of careful analysis.

\section{Conclusions}

The use of climate change information is, to different degrees, common in the decision-making processes of all the four case studies analysed. On the other hand, HECC scenarios are not commonly perceived as having higher likelihood, and thus, current decision-making processes do not routinely include HECC information in their frameworks. The primary reasons for this include lack of usability, inadequate contextualisation within broader decision-making needs, and/or insufficient availability of cross-sectoral and non-climatic (socioeconomic) information. Institutional settings and decision timeframes further inhibit the consideration of HECC scenarios in current adaptation (and to some extent mitigation) actions. Uncertainty is not generally perceived as a barrier to action but does play a significant role in decision support because of current reliance on climate-centred approaches. Further understanding of the individual and institutional challenges brought about by the 'conflict' between adapting to HECC or to more moderate levels of change as agreed in Paris is essential to better contextualise the use of climate change information. In turn, this would potentially provide

\footnotetext{
${ }^{4}$ One of the proposed objectives of this study was to assess both cross-sector and cross-scale adaptation decision-making processes. All case studies have different contexts and settings, e.g., most of the EU case decisions have to be implemented and monitored by its Member States whilst in national and local cases, those making decisions are also expected to assess and monitor its results. However, decisions made at higher levels are generally informed by the same scientific evidence (e.g., models, observations) and shape the boundaries and the decision spaces where lower level decisions are made. Therefore, whilst contexts differ, they are connected across scales, making common assessments a source of comparable and valuable insight on adaptation-related decision-making.
} 
the currently needed scope for decision-centred approaches to climate adaptation-related decision-making.

Acknowledgements The authors would like to thank all interview participants for their generous support and for offering their time and two anonymous reviewers for their comments that greatly improved an initial version of this manuscript.

Funding information The research leading to these results has received funding from the European Community's Seventh Framework Programme (FP7/2007-2013) under grant agreement no 603416, IMPRESSIONS Project (IMPRESSIONS - Impacts and Risks from High-End Scenarios: Strategies for Innovative Solutions (www. impressions-project.eu).

\section{Compliance with ethical standards}

Conflict of interest The authors declare that they have no conflict of interest.

Open Access This article is distributed under the terms of the Creative Commons Attribution 4.0 International License (http:// creativecommons.org/licenses/by/4.0/), which permits unrestricted use, distribution, and reproduction in any medium, provided you give appropriate credit to the original author(s) and the source, provide a link to the Creative Commons license, and indicate if changes were made.

\section{References}

Adger WN, Arnell NW, Tompkins EL (2005) Successful adaptation to climate change across scales. Glob Environ Chang 15:77-86. https://doi.org/10.1016/j.gloenvcha.2004.12.005

Adger WN, Agrawala S,. Mirza MMQ, Conde C, O’Brien K, Pulhin J, Pulwarty R, Smit B, Takahashi K (2007) Assessment of adaptation practices, options, constraints and capacity. In: Parry ML, Canziani OF, Palutikof JP, van der Linden PJ, Hanson CE (Eds.) Climate change 2007: impacts, adaptation and vulnerability, contribution of working group II to the fourth assessment report of the Intergovernmental Panel on Climate Change. Cambridge University Press, Cambridge, pp 717-743. ISBN: 978-052188010-7

Adger WN, Dessai S, Goulden M, Hulme M, Lorenzoni I, Nelson DR, Naess LO, Wolf J, Wreford A (2009) Are there social limits to adaptation to climate change? Clim Chang 93:335-354. https:// doi.org/10.1007/s10584-008-9520-Z

Alfieri L, Feyen L, Dottori F, Bianchi A (2015) Ensemble flood risk assessment in Europe under high end climate scenarios. Glob Environ Chang 35:199-212. https://doi.org/10.1016/j.gloenvcha. 2015.09.004

Biesbroek R, Dupuis J, Jordan A, Wellstead A, Howlett M, Cairney P, Rayner J, Davidson D (2015) Opening up the black box of adaptation decision-making. Nat Clim Chang 5:493-494. https://doi.org/ 10.1038 /nclimate2615

Bizikova L, Habtezion Z, Bellali J, Diakhite MM, Pinter L (2009) IEA training manual volume two: vulnerability and impact assessments for adaptation to climate change (VIA Module). United Nations Environment Program, Nairobi ISBN: 978-92-807-3072-2

Burch S (2010) Transforming barriers into enablers of action on climate change: insights from three municipal case studies in British
Columbia, Canada. Glob Environ Chang 20:287-297. https://doi. org/10.1016/j.gloenvcha.2009.11.009

Capela Lourenço T, Rovisco A, Groot A (2014) Chapter 3: making adaptation decisions under uncertainty: lessons from theory and practice. In: Capela Lourenço T, Rovisco A, Groot A, Nilsson C, Füssel H-M, Van Bree L, Street RB (eds) Adapting to an uncertain climate. Springer International Publishing, Heidelberg, pp 139-162 ISBN: 978-3-319-04875-8

Capela Lourenço T, Swart R, Goosen H, Street H (2016) The rise of demand-driven climate services. Nat Clim Chang 6:13-14. https:// doi.org/10.1038/nclimate2836

Dessai S, Lu X, Risbey JS (2005) On the role of climate scenarios for adaptation planning. Glob Environ Chang 15:87-97

Dessai S, van der Sluijs J (2007) Uncertainty and climate change adaptation: a scoping study. Copernicus Institute for Sustainable Development and Innovation, Utrecht ISBN: 978-90-8672-025-5

Dessai S, Hulme M, Lempert R, Pielke RA Jr (2009) Do we need better predictions to adapt to a changing climate? Eos 90:111-112

Dow K, Berkhout F, Preston BL, Klein RJT, Midgley G, Shaw MR (2013) Limits to adaptation. Nat Clim Chang 3:305-307

Dunn M, Rounsevell MD, Carlsen H, Dzebo A, Capela Lourenço T, Hagg J (2017) To what extent are land resource managers preparing for high-end climate change in Scotland? Clim Chang 141:181-195. https://doi.org/10.1007/s10584-016-1881-0

Dzebo A, Stripple J (2015) Transnational adaptation governance: an emerging fourth era of adaptation. Glob Environ Chang 35:423435. https://doi.org/10.1016/j.gloenvcha.2015.10.006

Edenhofer O, Pichs-Madruga R, Sokona Y, Kadner S, Minx JC, Brunner S, Agrawala S, Baiocchi G, Bashmakov IA, Blanco G, Broome J, Bruckner T, Bustamante M, Clarke L, Conte Grand M, Creutzig F, Cruz-Núñez X, Dhakal S, Dubash NK, Eickemeier P, Farahani E, Fischedick M, Fleurbaey M, Gerlagh R, Gómez-Echeverri L, Gupta S, Harnisch J, Jiang K, Jotzo F, Kartha S, Klasen S, Kolstad C, Krey V, Kunreuther H, Lucon O, Masera O, Mulugetta Y, Norgaard RB, Patt A, Ravindranath NH, Riahi K, Roy J, Sagar A, Schaeffer R, Schlömer S, Seto KC, Seyboth K, Sims R, Smith P, Somanathan E, Stavins R, von Stechow C, Sterner T, Sugiyama T, Suh S, ÜrgeVorsatz D, Urama K, Venables A, Victor DG, Weber E, Zhou D, Zou J, Zwickel T (2014) Technical summary. In: Climate change 2014: mitigation of climate change. In: Edenhofer O, Pichs-Madruga R, Sokona Y, Farahani E, Kadner S, Seyboth K, Adler A, Baum I, Brunner S, Eickemeier P, Kriemann B, Savolainen J, Schlömer S, von Stechow C, Zwickel T, Minx JC (eds) Contribution of Working Group III to the Fifth Assessment Report of the Intergovernmental Panel on Climate Change. Cambridge University Press, Cambridge ISBN: 978-1-107-05821-7

Eisenack K, Moser SC, Hoffmann E, Klein RJ, Oberlack C, Pechan A, Rotter M, Termeer CJ (2014) Explaining and overcoming barriers to climate change adaptation. Nat Clim Chang 4:867-872. https://doi. org/10.1038/nclimate2350

Eiser J, Bostrom A, Burton I, Johnston DM, McClure J, Paton D, van der Pligt J, White MP (2012) Risk interpretation and action: a conceptual framework for responses to natural hazards. Int J Disaster Risk Reduct 1:5-16. https://doi.org/10.1016/j.ijdrr.2012.05.002

Field CB, Barros VR, Mach KJ, Mastrandrea MD, van Aalst M, Adger WN, Arent DJ, Barnett J, Betts R, Bilir TE, Birkmann J, Carmin J, Chadee DD, Challinor AJ, Chatterjee M, Cramer W, Davidson DJ, Estrada YO, Gattuso J-P, Hijioka Y, Hoegh-Guldberg O, Huang HQ, Insarov GE, Jones RN, Kovats RS, Romero-Lankao P, Larsen JN, Losada IJ, Marengo JA, McLean RF, Mearns LO, Mechler R, Morton JF, Niang I, Oki T, Olwoch JM, Opondo M, Poloczanska ES, Pörtner H-O, Redsteer MH, Reisinger A, Revi A, Schmidt DN, Shaw MR, Solecki W, Stone DA, Stone JMR, Strzepek KM, Suarez AG, Tschakert P, Valentini R, Vicuña S, Villamizar A, Vincent KE, Warren R, White LL, Wilbanks TJ, Wong PP, Yohe GW, (2014) Technical summary. In: Field, CB, Barros VR, Dokken DJ, Mach 
KJ, Mastrandrea MD, Bilir TE, Chatterjee M, Ebi KL, Estrada YO, Genova RC, Girma B, Kissel ES, Levy AN, MacCracken S, Mastrandrea PR, White LL (eds) Climate change 2014: impacts, adaptation, and vulnerability. Part A: Global and sectoral aspects. Contribution of Working Group II to the Fifth Assessment Report of the Intergovernmental Panel on Climate Change. Cambridge University Press, Cambridge, pp. 35-94. ISBN: 978-1-107-05807-1

Gasser T, Guivarch C, Tachiiri K, Jones CD, Ciais P (2015) Negative emissions physically needed to keep global warming below $2{ }^{\circ} \mathrm{C}$. Nat Commun 6:7958. https://doi.org/10.1038/ncomms8958

Gramberger M, Zellmer K, Kok K, Metzger MJ (2015) Stakeholder integrated research (STIR): a new approach tested in climate change adaptation research. Clim Chang 128:201-214. https://doi.org/10. 1007/s10584-014-1225-x

Golledge NR, Kowalewski DE, Naish TR, Levy RH, Fogwill CJ, Gasson EG (2015) The multi-millennial Antarctic commitment to future sea-level rise. Nature 526:421-425. https://doi.org/10.1038/ nature 15706

Hulme M, Dessai S (2008) Negotiating future climates for public policy: a critical assessment of the development of climate scenarios for the UK. Environ Sci Pol 11:54-70. https://doi.org/10.1016/j.envsci. 2007.09.003

James R, Otto F, Parker H, Boyd E, Cornforth R, Mitchell D, Allen M (2014) Characterizing loss and damage from climate change. Nat Clim Chang 4:938-939. https://doi.org/10.1038/nclimate2411

Jordan A, Rayner T, Schroeder H, Adger N, Anderson K, Bows A, Quéré CL, Joshi M, Mander S, Vaughan N, Whitmarsh L (2013) Going beyond two degrees? The risks and opportunities of alternative options. Clim Pol 13(6):751-769. https://doi.org/10.1080/14693062. 2013.835705

Jones RN, Patwardhan A, Cohen SJ, Dessai S, Lammel A, Lempert RF, Mirza MMQ, von Storch H (2014) Foundations for decision making. In: Field CB, Barros VR, Dokken DJ, Mach KJ, Mastrandrea MD, Bilir TE, Chatterjee M, Ebi KL, Estrada YO, Genova RC, Girma B, Kissel ES, Levy AN, MacCracken S, Mastrandrea PR, White LL (eds.) Climate change 2014: impacts, adaptation, and vulnerability, Part A: Global and sectoral aspects, Contribution of Working Group II to the Fifth Assessment Report of the Intergovernmental Panel on Climate Change. Cambridge University Press, Cambridge, United Kingdom and New York, NY, USA, pp 195-228

Jones L, Champalle C, Chesterman S, Cramer L, Crane TA (2016) Constraining and enabling factors to using long-term climate information in decision-making. Clim Pol 17(5):551-572. https://doi. org/10.1080/14693062.2016.1191008

Kates RW, Clark WC, Corell R, Hall JM, Jaeger CC, Lowe I, McCarthy JJ, Schellnhuber HJ, Bolin B, Dickson NM, Faucheux S, Gallopin GC, Gruebler A, Huntley B, Jäger J, Jodha NS, Kasperson RE, Mabogunje A, Matson P, Mooney H, Moore IIIB, O'Riordan T, Svedin U (2001) Sustainability science. Science 292:641-642

Kirchhoff CJ, Carmen Lemos M, Dessai S (2013) Actionable knowledge for environmental decision making: broadening the usability of climate science. Annu Rev Environ Resour 38:393-414. https://doi. org/10.1146/annurev-environ-022112-112828

Klein RJT, Juhola S (2014) A framework for Nordic actor-oriented climate adaptation research. Environ Sci Pol 40:101-115

Lavell A, Oppenheimer M, Diop C, Hess J, Lempert R, Li J, Muir-Wood $\mathrm{R}$, Myeong, S (2012) Climate change: new dimensions in disaster risk, exposure, vulnerability, and resilience. In: Managing the risks of extreme events and disasters to advance climate change adaptation [Field, CB., Barros V, Stocker TF, Qin D, Dokken DJ, Ebi KL, Mastrandrea MD, Mach KJ, Plattner G-K,. Allen SK, Tignor M, Midgley PM (eds.)]. A Special Report of Working Groups I and II of the Intergovernmental Panel on Climate Change (IPCC). Cambridge University Press, Cambridge, UK, and New York, NY, USA, pp. 25-64. ISBN: 978-1-107-02506-6
Lemos MC, Kirchhoff CJ, Ramprasad V (2012) Narrowing the climate information usability gap. Nat Clim Chang 2:789-794. https://doi. org/10.1038/nclimate1614

Lempert R, Nakićenović N, Sarewitz D, Schlesinger ME (2004) Characterizing climate change uncertainties for decision-makers. Clim Chang 65:1-9

Lenton TM, Held H, Kriegler E, Hall JW, Lucht W, Rahmstorf S, Schellnhuber HJ (2008) Tipping elements in the Earth's climate system. Proc Natl Acad Sci 105:1786-1793. https://doi.org/10. 1073/pnas.0705414105

Lorenzoni I, Nicholson-Cole S, Whitmarsh L (2007) Barriers perceived to engaging with climate change among the UK public and their policy implications. Glob Environ Chang 17:445-459. https://doi. org/10.1016/j.gloenvcha.2007.01.004

Madsen MS, Maule CF, Christensen JH, Fronzek S, Carter TR (2016) IMPRESSIONS Project - Deliverable D2.3, IMPRESSIONS Climate Scenarios. Available at http:// impressions-project.eu

McNie EC (2007) Reconciling the supply of scientific information with user demands: an analysis of the problem and review of the literature. Environ Sci Pol 10:17-38. https://doi.org/10.1016/j.envsci. 2006.10.004

Moss RH, Edmonds JA, Hibbard KA, Manning MR, Rose SK, van Vuuren DP, Carter TR, Emori S, Kainuma M, Kram T, Meehl GA, Mitchell JFB, Nakicenovic N, Riahi K, Smith SJ, Stouffer RJ, Thomson AM, Weyant JP, Wilbanks TJ (2010) The next generation of scenarios for climate change research and assessment. Nature 463:747-756. https://doi.org/10.1038/ nature 08823

O'Brien K, Leichenko RM (2000) Double exposure: assessing the impacts of climate change within the context of economic globalization. Glob Environ Chang 10:221-232

O’Neill BC, Kriegler E, Riahi K, Ebi K, Hallegatte S, Carter TR, Mathur $R$, van Vuuren DP (2014) A new scenario framework for climate change research: the concept of shared socioeconomic pathways. Clim Chang 122:387-400. https://doi.org/10.1007/s10584-0130905-2

Pidgeon NF, Fischhoff B (2011) The role of social and decision sciences in communicating uncertain climate risks. Nat Clim Chang 1:35-41. https://doi.org/10.1038/nclimate 1080

Pohl C, Hadorn GH (2008) Core terms in transdisciplinary research. In: Hadorn GH, Hoffmann-Riem H, Biber-Klemm S, GrossenbacherMansuy W, Joye D, Pohl C, Wiesmann U, Zemp E (eds) Handbook of transdisciplinary research. Springer, Dordrecht, pp 427-432 ISBN: 978-1-4020-6698-6

Porter J, Dessai S, Tang S. (2012) Climate scenarios, decisionmaking and uncertainty: do users need what they want? Project ICAD, University of Leeds, UK. Available at: http:// www.icad.leeds.ac.uk/

Preston B, Mustelin J, Maloney M (2013) Climate adaptation heuristics and the science/policy divide. Mitig Adapt Strat G1 20:467-497. https://doi.org/10.1007/s11027-013-9503-x

Rayner T, Jordan A (2010) Adapting to a changing climate: an emerging European Union policy? In: Jordan A, Huitema D, van Asselt H, Rayner T, Berkout F (eds.) Cambridge University Press, Cambridge, UK, pp 145-166. ISBN: 978-0-521-19612-3

Sherwood SC, Huber M (2010) An adaptability limit to climate change due to heat stress. Proc Natl Acad Sci 107:9552-9555. https://doi. org/10.1073/pnas.0913352107

Stafford Smith M, Horrocks L, Harvey A, Hamilton C (2011) Rethinking adaptation for a 4 C world. Phil Trans R Soc A 369:196-216. https:// doi.org/10.1098/rsta.2010.0277

Schewe J, Heinke J, Gerten D, Haddeland I, Arnell NW, Clark DB, Dankers R, Eisner S, Fekete BM, Colón-González FJ, Gosling SN (2014) Multimodel assessment of water scarcity under climate 
change. Proc Natl Acad Sci 111:3245-3250. https://doi.org/10. 1073/pnas. 1222460110

Swart R, Biesbroek R, Capela Lourenço T (2014) Science of adaptation to climate change and science for adaptation. Front Environ Sci 2: 29. https://doi.org/10.3389/fenvs.2014.00029

Tompkins EL, Adger WN, Boyd E, Nicholson-Cole S, Weatherhead K, Arnell N (2010) Observed adaptation to climate change: UK evidence of transition to a well-adapting society. Glob Environ Chang 20:627635. https://doi.org/10.1016/j.gloenvcha.2010.05.001 van Vuuren DP, Edmonds J, Kainuma MLT, Riahi K, Thomson A, Matsui T, Hurtt G, Lamarque J-F, Meinshausen M, Smith S, Grainer C, Rose S, Hibbard KA, Nakicenovic N, Krey V, Kram T (2011) Representative concentration pathways: an overview. Clim Chang 109:5-31. https://doi.org/10.1007/s10584-011-0148-z

Willows R, Connell R (2003) Climate adaptation: risk, uncertainty and decision-making, UKCIP Technical Report, UKCIP, Oxford. ISBN: 0-9544830-0-6 